\title{
Fire Protection of Technical Systems in Slovak Automotive Companies
}

\author{
A.Osvald ${ }^{1 *}$, L.Makovická Osvaldová ${ }^{2}$, P.Makovický ${ }^{3}$ \\ ${ }^{1}$ Technical University of Zvolen, Faculty of wood science and technology, Department of fire protection \\ 2University of Zilina, Faculty of special Engineering, Department of fire engineering \\ 3Kia Motors Slovakia, s.r.o.
}

\section{KEY WORDS}

Safety, fire protection, automotive companies, prevention, fire utility.

\begin{abstract}
Safety is very important for all people. Also safety of technical system is very important for machinery, equipments or production lines, especially in automotive companies. However we can divide safety to two parts. One part is occupational safety and health protection at work and second part is fire protection. In our article we want introduce Slovak automotive companies, technical system in automotive companies and finally introduce with fire protection in automotive companies.
\end{abstract}

\section{Introduction}

Safety represent very important part of every day lives all of us. Every day we are met with safety, in which is dominated fire protection. Actual statistic $v$ fire protection in Slovak republic is talk about 100450 fires in calendar year 2009, and killing 44 people and injury 171 people. At the same time we can safety characterized as property of object, equipment, technology, activity, or property of buildings keep their structures and properties against defect witch can attempt life of people.

On base of this, we can tell that safety can by divide it on problematic of safety and health care by the work and on problematic of fire protection

Fire protection represents special area, by witch in frame of safety we deal also with rise and behaviour of fire. Development of ideas of solving prevention methods are made in evolution of rules and statutory orders, witch skip from personal intervention (women's, children's ...) and technology (protection of rotated parts, machinery,...) to organized and conceptual arrangements.

Regarding on facts of development industrial parks In Slovak republic is this problematic very actual. In Slovakia we have three automotive companies, which represent tops of technology and technological process. Fire protection in each of these automotive companies represents number one in safety of automotive company. Operating process represent details planning of methods that are realised in operating halls.

\section{Automotive Companies in Slovakia}

Generally in automotive industry we have five shops - press, body, paint, assembly and engine shop.

The production process of a car starts at the press shop, where outer and some inner parts of a car body are manufactured. The automatic press lines, which enable us to reach high production efficiency and quality, are used for the production of parts, called panels. Main press lines will produce more than 60 various panel types. The 
quality of produced panels is checked in detail by using an unique optical inspection 3D system that can distinguish even the smallest defects on the surface. The auto palletizing system loads manufactured parts on pallets using four robots at each production line. Side body panels are conveyed to the automatic storage by the electric monorail system. Based on requests made by the production, panels are automatically delivered to the body shop.

The production of a car further continues at the body shop, where dimensionally accurate car bodies, identical in shape as well, are made by putting together and welding of subassemblies such as floor, left and right side structure and roof assembly. Dimensions of each body are controlled by the automatic control system, which utilizes robots equipped by laser sensors. The most important feature of the body shop is the possibility to simultaneously manufacture up to 8 different car models on the same line.

The paint shop is the next stop within the production process, in terms of which a car body goes through various surface treatments and gets the final color. The total length of the conveyor system, on which a body passes through particular treatments including buffer zones, is $7.5 \mathrm{~km}$. Just water borne paints are used at the paint shop and a total of 46 robots participate in the sealer and paint application. In pretreatment and electrochemical coating processes, a unique rotation-dipping system is used, thanks to which a protection substance gets to the most inaccessible parts of a body. The working environment requires special conditions such as dust-free operation, stable air humidity and temperature that are ensured by utilizing the air-handling system.

Only one carmaker in Slovakia is producing engines. It manufactures four types of engines; 1.4 and $1.6 \mathrm{~L}$ gasoline engines and 1.6 and $2.0 \mathrm{~L}$ diesel engines. At the engine shop, three metal cutting lines operate and produce cylinder blocks, cylinder heads and crank shafts. In addition, the assembly line for completing engines is also situated at the engine shop. Production lines are fully flexible and able to produce various engine types at once by using adaptable devices. This enables us to operatively react on customers' needs.

The assembly shop is the biggest shop of all production halls, in which the assembly and final completion of a car proceed. Bigger parts such as tank, exhaust pipe and seats are assembled with manipulators, which contribute to less physical effort of operators. Oversized and delicate parts such as cockpit, chassis and glasses are assembled by fully automated robots ensuring higher assembly efficiency and quality. At the end of the production process, an assembled car goes through final checking and is ready for dispatch to a customer.

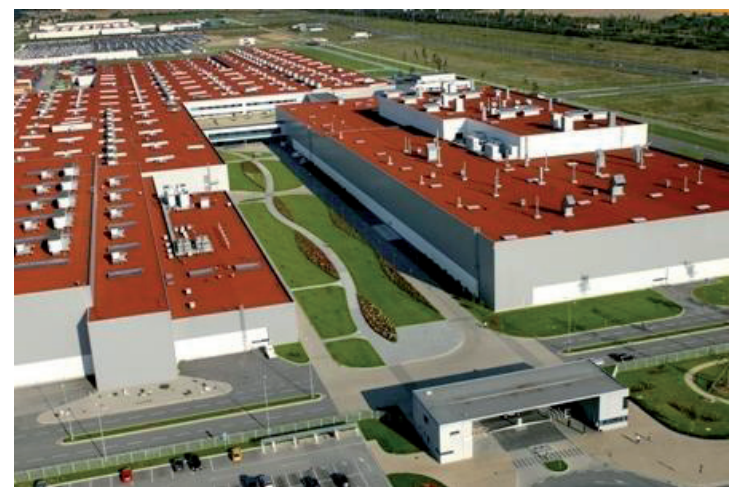

Fig. 1: Aerial views of automotive company

The worst dangerous object in automotive industry is represents by paint shop. The building is one-floor hall structure with inserted technological platforms. The structure of the building is made of reinforced concrete bearing elements. Vertical structures are prefabricated reinforced concrete and steel pillars, horizontal structures are made of prefabricated lintels posed on pillars consoles in the transversal direction of the building, of prefabricated reinforced steel slab composed of filigree slabs and monolithic concrete application.

The circumferential casing is designed as mounted and attached to pillars of the circumferential bearing structure with the spacing of $10,0 \mathrm{~m}$. Modules intended for the façade structure will be principally winded against effects of wind every 5 $\mathrm{m}$ by means of inserted steel pillars. The circumferential structure consists of reinforce concrete base panel reaching up to $+0,250 \mathrm{~m}$ around the whole building and a light circumferential casing made of sandwich panels, having both surfaces made of profiled galvanized sheet and thermal insulation of mineral fibers.

The bearing structure of the roof is designed of steel lattice beams. The roofing is composed of trapezoidal sheets, moisture stop, thermal insula- 
tion made of mineral fibers and water insulation.

The structure of internal room will be made of dividing walls, concrete or brick blocks, plastered cards and glass. The ceiling of these rooms will be on the 1st floor made of lower part of the reinforce concrete slab platform or of plastered card plates $+6,50 \mathrm{~m}$ and on the 2 nd floor made of light plastered card plates.

\subsection{Technological production process}

These are basic, gradually linked processes, as follows:

\section{- Transportation from body shop, \\ - Preliminary preparation,}

- Electrolytic galvanizing priming, including drying process,

- Inspection of priming,

- Tightening of spaces,

- Primer, including drying process,

- Inspection of primer,

- Basic coat, including drying process,

- Finish coating, including firing,

- Inspection, polishing, repairs,

- Final inspection,

- Transportation to the assembly shop.

Technological sections of the paint shop are divided and positioned so that the need to build underground chambers and channels is avoided. The building structure is designed as a unit, in which every body work passes through all technological procedures.

The body work is after completion of welding operation in the welding shop is suspended on skid carriage for the transportation made by the conveyor on the connection bridge to the paint shop. Body works on skid carriages are transported to the phosphorate line and to the electrolytic galvanization priming line by means of an automatic transporting system. After drying made in the drying oven the body work is automatically suspended on the skid and then the skid is transported to the sealing line. After the completion of the body work priming, the tightening, primer application and drying are carried out. Further operations are spraying, robotized application of the basic coat and after the drying process the application of the finish coat and drying in the oven.

The complete inspection is very detailed and demanding process and it results in various small or important repairs or retouches of the body work painting. The final inspection, which is aimed at verification of the absolute quality of each body work is followed by the waxing of cavities and transportation to shipment priming stock with finished body works. Here all body works wait for a further instruction of the transportation control system for being released and transferred through the bridge connecting the paint shop and assembly shop. At the end of the bridge in the paint shop each body work is automatically taken from the skid and suspended on the transport suspender going to the assembly shop.

Basic technological operations are supported by various supporting technologies, which have to be rated in accordance with the basic capacity of the paint shop.

The fire safety of the Paint Shop is dealt in accordance with the Regulation of the Ministry of Interior of Slovak Republic No. 94/2004 Coll., which institutes technical requirements related to the fire safety at construction of buildings and their utilization (hereinafter referred as to the "Regulation"), with the Regulation of Ministry of Interior of Slovak Republic No. 142/2004 Coll., which institutes principles of the fire safety at construction, utilization and operation of plants and other premises, in which surface treatment operations of various products are carried out by means of painting agents, with the Regulation of Ministry of Interior of Slovak Republic No. 96/2004Coll., which institutes principles of fire safety related to handling and warehousing of inflammable liquids, heavy heating oils and animal and vegetal greases and oils, with the STN 920201 standard "Fire safety of constructions, Common provisions" and other related standards.

The unit is a one floor level building with an inbuilt technological platform, alias mezzanine and a technological level, where the machine room of the air venting system is situated and which is situated as the last elevated floor without a permanent of temporary working position. In accordance with the $\S 5$ the mezzanine is not to be considered as a fire level, on its floor there are openings with the total ground surface of $22 \%$ of the lower fire level.

\subsection{Technical and technological equipment}

The confirmation of fire safety of individual technological equipment of the paint shop is not the subject of the present project documentation. The 
utilization and operation of the paint shop has to be in accordance with the Regulation No. 142/2004 Coll., and related prescriptions.

\subsubsection{General conditions}

Production equipment shall be made of uninflammable material or of such material that in case of fire does not significantly changes its properties and does not participate in fire propagation, and they will be designated so that due to the power supply stopping their safety is not endangered.

Supply hoses of production equipment aimed at transport of coating substances and diluents will be made of electrostatic conductive material. Metallic parts of production equipment including pipe distribution for coating substances and diluents will be conductively interconnected and grounded. Production equipment for surface treatment operations of products made of electrically conductive materials with the total surface exceeding 0,5 m2, allow the grounding of these products.

The content of supplying pipe distribution containing coating substances and diluents, may be in case of an accident, emptied and these pipes will be disposed so that they can not be heated up to the temperature higher than ignition temperature of the transported liquid reduced by $50^{\circ} \mathrm{C}$.

\subsubsection{Spraying booths}

No spraying booth is designed within the technological process of the paint shop, where both automatic and manual application of coating substances is carried out. These operations are divided into separated cages.

Spraying equipment are executed so that in case of an interruption of the exhausting of the spraying booth or in case of stopped operation of the continuous transport equipment the supply of coating substances will be interrupted too. Doors giving to the spraying booth of the automatic or manual coating substance application or giving to an area of their application will be equipped with metallic door contacts, which will stop the production equipment if doors are opened; these contacts may not influence operation of equipment aimed at the protection against fire and explosion. The industrial robot has to be realized and positioned so that its operation may not influence functions of equipment aimed at the protection against fire and explosion.

Spraying booths will be equipped with devices aimed at the protection against fire or explosion according to requirements.

\subsubsection{Drying ovens}

A drying oven uses a gaseous fuel and is heated up indirectly; system of burners of the heating equipment is situated outside the area of drying tunnels. Equipment for the temperature monitoring are installed in the inside area of the drying oven. The heating equipment is automatically stopped in case of any failure of the drying tunnel evacuation.

The temperature of surface parts of heating equipment must be lower by at least $50^{\circ} \mathrm{C}$ as the ignition temperature of coating substances or their diluents. Heating equipment shall be positioned so that coating substances may not drop on them from dried products.

\subsubsection{Transport equipment}

When coating substances are transported within an electric field, transport equipment have to be executed so that the value of leaky resistance of the spraying device prescribed by the manufacturer is not exceeded and that at the place of contact with product no spark jumps.

The continuous transport equipment for application of coating substances in spraying cages for an automatic application will be realized so that their start up is not possible if the exhausting equipment is not in operation at the same time.

\subsubsection{Air venting system equipment}

The air exchange in paint shops and drying ovens have to be ensured by means of a under pressure method; if particular requirements for dust free environment are presented, then venting in the paint shop may be carried out by means of an over pressure method; smokes and vapors from operation are voided to be spread into surroundings areas. A sufficient air exchange ensures that the concentration of dangerous substances in any place of plant does not exceed $25 \%$ of the lower limit of explosion.

Outlets from the exhausting pipe of the air venting equipment over the building roof are distanced at least 1,5 $\mathrm{m}$ from building structures made of inflammable materials and they ensure a dispersion 
of contamination matters so that they can not be inducted back to the operation plant.

Air venting system equipment and devices are equipped with a efficient filter aimed at retaining inflammable aerosols coming from coating substances and their diluents (for example: in spraying ovens the retention of water is ensured) and they are equipped with fire flaps in order to avoid the propagation of fire between individual fire sections. The building disposes of two machine rooms of the air venting system, where the first one is determined only for one fire section (production hall) and the second one for more fire sections (inbuilt premises).

\subsubsection{Electric installations}

The electric installation is carried out regarding the determined environment as per official records. Electric equipment and devices, which have to be in operation even during fire (emergency lighting, fire fighting technical equipment and devices) are ensured in accordance with the Regulation by means of a permanent supply of power energy from two independent sources (electric network and standby source - diesel generator, UPS or accumulator) by cables in accordance with the Regulation. The switching to another power supply is automatic.

Emergency lighting are installed and marked in the following:

\section{- All escape passages and exits,}

- Machine rooms of air venting system equipment, - Control rooms,

- Warehouses and processes with inflammable liquids.

The electrostatic conductive floor is made in:

a) Paint shops with the zone 1,

b) Paint shops with the zone 2 only for manual application of coating substances.

Emergency STOP pushbuttons enabling the stopping of equipment in case of fire are situated in the paint shop hall.

The building is equipped with a lightning conductor.

\subsubsection{Heating}

The heating of the building is designed in accordance with the STN 920300 standard "The fire safety of local heating devices and heat sources. The heating of hall is designed to be by hot air by means of air venting units. The heating of inbuilt premises is designed to be ensured by electric convector elements, dressing rooms and washing rooms are to be heated by the air venting system. The machine room of the air venting system is heated by gas heating units and convectors.

\subsubsection{Inflammable liquids}

Requirements related to the fire safety are dealt in accordance with the Regulation No. 96/2004 Coll., which institutes principles of fire safety in case of handling and warehousing of inflammable substances and liquids, heavy heating oils, vegetable and animal oils and greases, the STN 920800 standard "Inflammable liquids, Operation plant and warehouses".

The technological process, for the purposes of surface treatment operations, uses liquids that are composed of paints and diluents. Two types of paints are used:

\section{- Water down paints (Primer, Basic Coat), \\ - Inflammable liquids (Clear Coat).}

Volumes of paints in warehouses and paint mixing plant are as follows:

\subsection{Paints based on diluents \\ 4.500 I Water down paints}

Diluents based paints are classified into 2 nd class of danger (ignition point $>27^{\circ} \mathrm{C}$ ). Water down paints has before their dissolution the ignition point of $61-93^{\circ} \mathrm{C}$. Water down paints is supplied to warehouses only in dissolved conditions.

The area of paint shop, coating substance preparation hall and ready to use warehouse, where inflammable liquids or coating substances creating with air explosive gaseous atmosphere are used, have to be equipped with the floor down sloped towards to the collection or emergency tank. Warehouses and operation halls containing inflammable liquids will be equipped with an emergency or collecting tank. The volume of an emergency tank is dimensioned in accordance with the STN 92 0800 standard to $10 \%$ of warehoused inflammable liquid volume, but not less than the volume of the biggest transported package. The emergency tank of the operation hall is of such volume that it may retain at least:

\section{a) The volume of inflammable liquids in the biggest tank or b) $60 \%$ of inflammable liquids that are in technological equipment or are prepare for them during}

1. 5 minutes, if the equipment is equipped with a 
stopper situated above the entry to the operation hall, which automatically interrupts the supply of inflammable liquids if their volume, pressure of temperature are changed in comparison to determined values,

\section{15 minutes in other cases.}

The emergency tank in the warehouse of inflammable liquids is represented by the floors, which is made of uninflammable materials and resistant to chemical effects of inflammable liquids. The bottom part of the emergency tank is down sloped towards the gathering tank.

The venting of the warehouse of inflammable liquids is endured even during the current operation by a forced venting with at least a double exchange of air per hour. The forced venting ensures at least ten times of volume of exchanged air per hour.

Metallic structures of buildings and their parts, where inflammable liquids are warehoused or handled, have to be conductively interconnected, grounded and protected against effects of the atmospheric electricity. Metallic parts of technological equipment and tanks have to be conductively interconnected, grounded and protected against effects of the atmospheric electricity. No cable channels accessible from the upper part are situated in the paint shop.

\section{Conclusion}

Increase of fire can be reach by different combination of situation. Possible situation and theirs combination are in marked way conditional by individual key equipments technical systems.

Probability of increasing fire is different; there out will be result of risk. By appraisals expectation of rising of fire and impact rising of individual situation is necessary come out from technical parameters of individual equipments.

Knowing of operating process and installation of fire protection equipments (fire alarm system, fireextinguishers, fire hydrants, ...) on the results of fire analyses by Regulation No. 611/2006 regarding the operating process or by using materials in individual operating process. Also is very necessary regarding elimination of fire risk, iteration education of employees' about fire protection. All this steps are very important by prevention of fire risks in automotive companies.

\section{References}

[1] Zelený, J.: Riziká v priemysle. Zvolen: Technická univerzita vo Zvolene, 2006, ISBN 80-228-1244-7.

[2] Regulation of the Ministry of Interior of Slovak Republic No. 611/2006 Coll., which institutes fire brigades

[3] Regulation of the National Council of Slovak Republic No. 314/2001 Coll., which institutes fire protection

[4] Regulation of the Ministry of Interior of Slovak Republic No. 94/2004 Coll., which institutes technical requirements related to the fire safety at construction of buildings and their utilization

[5] Regulation of Ministry of Interior of Slovak Republic No 142/2004 Coll., which institutes principles of the fire safety at construction, utilization and operation of plants and other premises, in which surface treatment operations of various products are carried out by means of painting agents

[6] Regulation of Ministry of Interior of Slovak Republic No. 96/2004Coll., which institutes principles of fire safety related to handling and warehousing of inflammable liquids, heavy heating oils and animal and vegetal greases and oils

[7] STN 920201 standard "Fire safety of constructions, Common provisions"

[8] STN 920300 standard "The fire safety of local heating devices and heat sources"

[9] STN 920800 standard "Inflammable liquids, Operation plant and warehouses"

[10] <http://eng.kia.sk/index.php?context=303> [2009-12-14] 